\title{
Correlation Between Hip Abductor Strength and Navicular Drop
}

\author{
David Edwards*, Elisabeth Coombs and Daniel Savoie \\ Wheeling Jesuit University, USA
}

Submission: November 07, 2017; Published: June 26, 2018

*Corresponding author: David Edwards, Wheeling Jesuit University, USA, Email: dedwards@wju.edu

\begin{abstract}
Objectives: To determine if there is a correlation between hip abductor strength and navicular drop.

Methods: This study consisted of 58 subjects between the ages of 18 and 35. Hip abductor strength and navicular drop were measured on each subject's dominant leg. A Pearson Correlation and Linear regression analysis was completed to determine if there was a correlation or predictive relationship between hip abductor strength and excessive navicular drop.

Results: Through analysis using a Pearson Correlation and Linear Regression in the SPSS program, it was found that there were no statistical relationship between the strength of the hip abductors and navicular drop in the group as a whole or for males and females individually.

Conclusion: This study suggests that there is no significant correlation between the strength of the hip abductors and navicular drop in this population. In the female only grouping, there was a shift closer to statistical significance. One limitation is that body weight was not considered a factor when measuring hip abductor strength, which could skew results. The age and activity level of the population sampled may also have played a role in the significance of this study as only younger and active patients were involved.
\end{abstract}

\section{Introduction}

Strength of the hip and body biomechanics are an important part of the overall health of an individual. If a person displays abnormal biomechanics, it can lead to an increased risk of injury. When evaluating the lower extremity, the kinetic chain that plays a vital role in maintaining proper body mechanics for gait and overall posture. This chain includes the hip, knee, and ankle joints. If the biomechanics of one of these joints is impaired it can lead to an alteration in position of another, and this can continue down the chain. Previous research has endeavored to study the relationships between these joints and define the underlying factors that can cause these alterations. Some of these studies specifically investigated the relationship between the strength of the hip musculature and its relationship with the positioning of the knee and ankle.

Hollman et al (2006) looked at the correlation between hip strength and its relationship to foot and knee posture in a standing position. The study utilized thirty-three subjects between the ages of 22 to 31 . The strength of the subject's hip adductors, abductors, external rotators, and internal rotators were measured using a dynamometer and correlated to medial arch height. Overall the study found that reduced strength of hip abductors relative to hip adductors is associated with increased pronation of the foot [1].

Goo et al (2016) examined the effects of the gluteus maximus and abductor hallucis muscles on navicular drop. A total of 18 healthy adults were selected after excluding those with arthritis, foot abnormalities, diabetes, or history of foot surgery. All subjects had foot pronation $(>10 \mathrm{~mm}$ ) when performing the navicular drop test. One group of participants performed gluteus maximus and abductor hallucis strengthening exercises while the other group performed just abductor hallucis strengthening exercises. The results showed that navicular drop decreased significantly more in subjects performing gluteus maximus and abductor hallucis strengthening exercises than the group performing only abductor hallucis strengthening exercise. Given these results it was concluded that performing strengthening of the gluteus maximus as well as the adductor hallucis was more effective in correcting overpronation than abductor hallucis strengthening alone [2].

Chuter et al (2012) investigated the link between prolonged foot pronation and the injuries that could result from the change in biomechanics. This included injuries such as stress fractures, patellofemoral pain, and ACL tears. Excessive foot pronation has also been correlated with other changes in positioning such as internal tibial and femoral rotation. Despite all of these assumed correlations with foot pronation and injury, the authors stated that there is actually very little evidence to support these claims. The majority of the studies that have been done have been poor quality with small sample sizes. Kosahvili et al. [3] investigated correlation between pes planus and the incidence of low back pain. They found that individuals with moderate or severe pes 
planus had a higher rate of anterior knee pain and intermittent low back pain [4].

Today, over pronation is commonly treated with orthotics. A systematic review conducted by Banwell et al (2014) looked at the effectiveness of orthotics in adults with flexible pes planus. The systematic review was concerned with outcomes such as foot pain, kinematics and kinetics as well the physical function of the foot. The study concluded that there was little quality evidence that supported the notion that foot orthoses improve pain, reduce rearfoot inversion and eversion and change loading or impact forces [5]. With lack of significant research showing improvements in pain using orthotics, past researchers have looked for a more proximal solution, such as hip abductor weakness as a potential cause of over pronation.

The current study aimed to build on past research to determine if a correlation between hip abductor strength and foot pronation exists.

\section{Methods}

This study included a correlational study assessing relationship between navicular drop and hip abductor strength. The researchers attained IRB approval and then recruited 68 subjects through a sample of convenience with written consent obtained prior to completion of testing. Subjects between the ages of 18 and 35 with no recent lower extremity injury that required missed work time in the last six months were included in the study. Subjects with lower extremity surgery in the past year were excluded from the study. Subjects were recruited from area gyms Results in Ohio County, WV. The dominant leg was determined and used for both measurements taken for this study. Hip abductor strength was then measured three times on each leg with thirty second rest times in between tests using a handheld dynamometer (Hoggan Scientific LLC, microFET) following procedures outlined in Muscles Testing and Function with Posture and Pain [6]. The subject was side-lying with bottom leg flexed at the hip and knee and the pelvis rotated slightly forward and tested hip in slight external rotation [6].

The examiner stabilized the pelvis as pressure was applied with the dynamometer just proximal to the ankle in the direction of adduction and slight flexion. Handheld dynamometry has been found to have excellent reliability [7]. Navicular drop was then measured on the dominant foot using the protocol found in Orthopedic Physical Assessment [8]. To perform the test the patient was be put in talar neutral while standing through use of pinch grip maneuver [8]. A mark was placed on the navicular tuberosity and the height in millimeters was measured from that point to the ground using a standard ruler [8]. Patient then assumed a normal relaxed standing position and the measurement was repeated [8]. Any difference between the two measurements greater than $10 \mathrm{~mm}$ is considered abnormal and indicates excessive foot pronation [8]. Navicular drop test has shown good inter- and intra-rater reliability [9]. A Pearson Correlation and correlation matrix was then used to compare the strongest hip abduction measurement with the corresponding navicular drop measurement of the same dominant side for males and females and as a group overall.

\section{Average Hip Abduction Strength vs Navicular Drop}

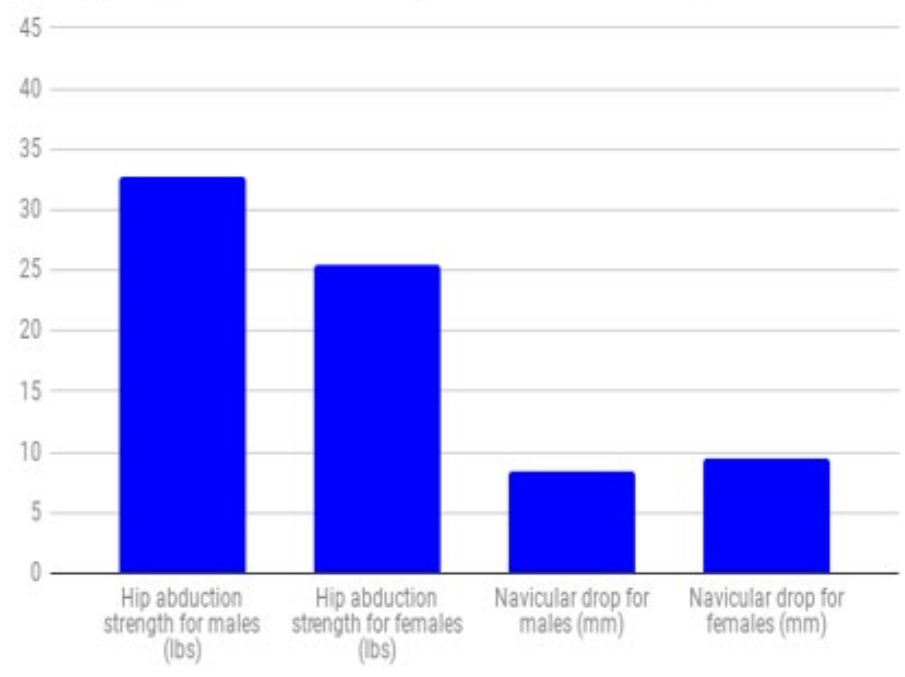

Figure 1: Average hip abduction strength vs navicular drop.

There were a total of 68 individuals assessed in the study. Of the total participants, 28 of the subjects were male (41\%) were male and 40 were female (59\%). A Pearson Correlation and linear regression analysis was completed assessing the relationship between navicular drop and hip abduction strength on three different subsets of the data. These subsets included: the entire population of the study, males only, and females only. The mean hip abduction strength was 28.47 pounds and the mean navicular drop for the entire population was 9.06 millimeters. Within the entire population of the study the Pearson Correlation ( $p=0.586$ ) 
and linear regression $(\mathrm{p}=0.586)$ showed no significance. The mean hip abductor strength for males was 32.74 pounds and the mean navicular drop was 8.36 millimeters. In the male only subset of the data, the Pearson correlation $(p=0.295)$ and linear regression $(p=0.295)$ did not show a significant correlation. The mean hip abductor strength for females was 25.48 pounds and the mean navicular drop was $9.55 \mathrm{~mm}$. The female only subset showed a trend toward significance in the Pearson Correlation $(p=0.094)$ and linear regression $(p=0.094)$ but overall was still not statistically significant $(\mathrm{p}=0.094)$ (Figure 1,2).

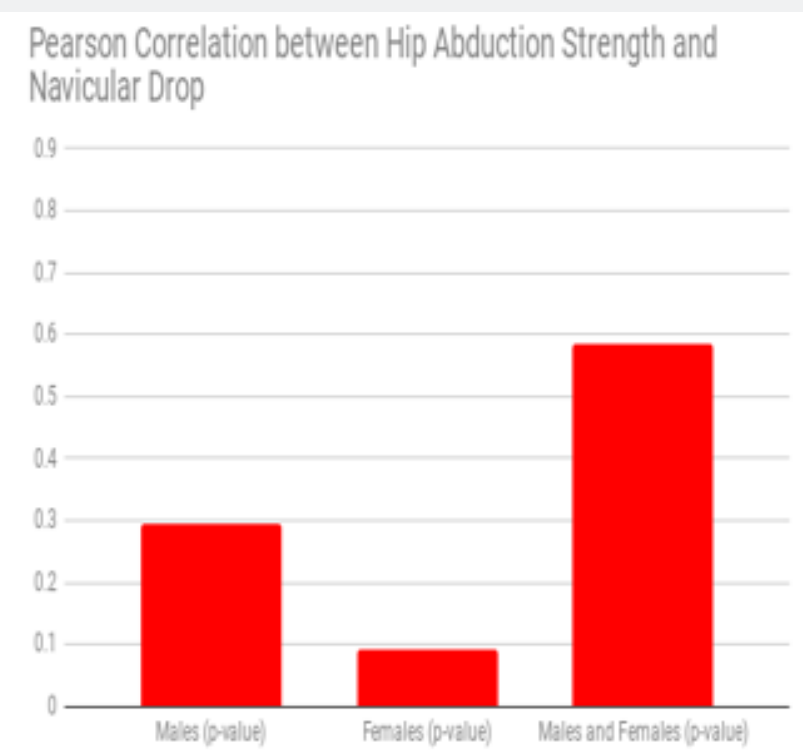

Figure 2: Pearson correlation between hip abduction strength and navicular drop.

\section{Conclusion}

Our current findings suggest that there is no significant correlation between hip abductor strength and foot pronation. These results are important considering some of the past literature suggested that a relationship exists [1]. It may be beneficial to examine other causes of foot pronation that could have a compounding effect with weak hip abductors. For example, a recent study looked at the relationship between fatigue of the foot intrinsic muscles and the relationship to the integrity of the medial longitudinal arch. Navicular drop was measured and then the subjects went through a bout of exercise targeting the foot intrinsic muscles so that the muscles were fatigued. At this point navicular drop was then reassessed. Overall the study found that when the intrinsic muscles of the foot were fatigued there was a significant difference in foot pronation as assessed by navicular drop [10].

One limitation in the current study is the sample size and population. The sample size could have been larger ( 40 females, 28 males) and the population could have been more diverse considering most of the participants were college students in their mid-twenties. College students tend to be more active which is not a good representation for the general population. Lastly, this study did not include body weights of patients. It is possible that a heavier person will be stronger than a lighter person regardless of foot pronation. Potential suggestions for future research should include larger and more diverse populations as well as considering the body weight of each patient.

In summary, the current research did not validate a correlation between navicular drop and foot pronation in a sample of young males and females. However, only 40 females in the total sample of 68 was analyzed individually and the trend was moving toward a significant relationship with this limited sample size when only female abduction strength and navicular drop was correlated, and males were removed. Further research should be completed with a larger sample size of only females to assess if a relationship exists when the sample size is increased.

\section{References}

1. Hollman JH, Kolbeck KE, Hitchcock JL, Koverman JW, Krause DA (2006) Correlations between hip strength and static foot and knee posture. Journal of Sport Rehabilitation 15(1): 12-23.

2. Goo YM, Kim TH, Lim JY (2016) The effects of gluteus maximus and abductor hallucis strengthening exercises four weeks on navicular drop and lower extremity muscle activity during gait with flatfoot. Journal of Physical Therapy Science 28(3): 911-915.

3. Chuter VH, Jonge X (2012) Proximal and distal contributions to lower extremity injury: a review of the literature. Gait \& Posture 36(1): 7-15.

4. Kosahvili Y, Fridman T, Backstein D, Safir O, Ziv Y (2008) The correlation between pes planus and anterior knee or intermittent low back pain. Foot \& Ankle International 29(9): 910-913.

5. Banwell H, Mackintosh S, Thewlis D (2014) Foot orthoses for adults with flexible pes planus: a systematic review. Journal of Foot and Ankle Research 7: 23.

6. Kendall FP, McCreary EK, Provance PG, Rodgers MM, Romani WA, et al. (2005) Muscles: testing and function with posture and pain. Lippincott Williams \& Wilkins, Baltimore, USA.

7. Kim WK, Kim D, Seo KM, Kang SH (2014) Reliability and Validity of Isometric Knee Extensor Strength Test With Hand-Held Dynamometer Depending on Its Fixation: A Pilot Study 38(1): 84-93.

8. Magee DJ (2014) Orthopedic physical assessment. Elsevier Saunders, St. Louis, USA. 
9. Deng J, Joseph R, Wong C (2016) Reliability and validity of the navicular drop test: do static measures of navicular height relate to dynamic navicular motion during gait?

This work is licensed under Creative Commons Attribution 4.0 License

DOI: 10.19080/JYP.2018.05.555667
10. Headlee D, Leonard J, Hart J, Ingersoll C, Hertel J (2008) Fatigue of the plantar intrinsic foot muscles increases navicular drop. J Electromyogr Kinesiol 18(3): 420-425.

\section{Your next submission with Juniper Publishers} will reach you the below assets

- Quality Editorial service

- Swift Peer Review

- Reprints availability

- E-prints Service

- Manuscript Podcast for convenient understanding

- Global attainment for your research

- Manuscript accessibility in different formats ( Pdf, E-pub, Full Text, Audio)

- Unceasing customer service

Track the below URL for one-step submission https://juniperpublishers.com/online-submission.php 